\title{
Spatial Variability and Application of Ratios between BTEX in Two Canadian Cities
}

\author{
Lindsay Miller, ${ }^{1}$ Xiaohong Xu, ${ }_{1}^{1}$ Amanda Wheeler, ${ }^{2}$ Dominic Odwa Atari, ${ }^{3}$ \\ Alice Grgicak-Mannion, ${ }^{4}$ and Isaac Luginaah ${ }^{5}$ \\ ${ }^{1}$ Department of Civil and Environmental Engineering, University of Windsor, \\ Windsor, ON, Canada N9B 3P4 \\ ${ }^{2}$ Air Health Science Division, Health Canada, Ottawa, ON, Canada K1A OK9 \\ ${ }^{3}$ Department of Geography, Nipissing University, North Bay, ON, Canada N1B 8L7 \\ ${ }^{4}$ Great Lakes Institute for Environmental Research, University of Windsor, \\ Windsor, ON, Canada N9B 3P4 \\ ${ }^{5}$ Department of Geography, University of Western Ontario, London, Ontario, Canada
}

Received 5 November 2011; Accepted 23 December 2011

Academic Editor: Ki-Hyun Kim

\begin{abstract}
Spatial monitoring campaigns of volatile organic compounds were carried out in two similarly sized urban industrial cities, Windsor and Sarnia, ON, Canada. For Windsor, data were obtained for all four seasons at approximately 50 sites in each season (winter, spring, summer, and fall) over a three-year period $(2004,2005$, and 2006) for a total of 12 sampling sessions. Sampling in Sarnia took place at 37 monitoring sites in fall 2005. In both cities, passive sampling was done using $3 \mathrm{M}$ 3500 organic vapor samplers. This paper characterizes benzene, toluene, ethylbenzene, 0 , and $(m+p)$-xylene (BTEX) concentrations and relationships among BTEX species in the two cities during the fall sampling periods. BTEX concentration levels and rank order among the species were similar between the two cities. In Sarnia, the relationships between the BTEX species varied depending on location. Correlation analysis between land use and concentration ratios showed a strong influence from local industries. Use one of the ratios between the BTEX species to diagnose photochemical age may be biased due to point source emissions, for example, 53 tonnes of benzene and 86 tonnes of toluene in Sarnia. However, considering multiple ratios leads to better conclusions regarding photochemical aging. Ratios obtained in the sampling campaigns showed significant deviation from those obtained at central monitoring stations, with less difference in the $(m+p) /$ E ratio but better overall agreement in Windsor than in Sarnia.
\end{abstract}

KEYWORDS: volatile organic compounds, BTEX, inter-species ratios, photochemical age, spatial variability. 


\section{INTRODUCTION}

Volatile organic compounds (VOCs), specifically benzene, toluene, ethylbenzene, $o$-xylene, and $(m+p)$ xylene (BTEX), have been the focus of several recent studies [1-4] due to the adverse health effects, including cancer, associated with their exposure. Spatial monitoring campaigns were done in two similarly sized urban industrial cities in southwestern ON, Canada: Windsor $\left(42^{\circ} 16^{\prime} \mathrm{N}, 82^{\circ} 58^{\prime} \mathrm{W}\right)$ and Sarnia $\left(42^{\circ}\right.$ $\left.58^{\prime} \mathrm{N}, 82^{\circ} 23^{\prime} \mathrm{W}\right)$. Windsor has an area of $147 \mathrm{~km}^{2}$ and a population of 218,473 , while Sarnia has an area of $165 \mathrm{~km}^{2}$ and a population of 70,876 [5]. The two study areas are shown in Figure 1. The geography of both cities is relatively flat, with elevations above sea level of 190 and $191 \mathrm{~m}$, respectively. Sarnia is located approximately $100 \mathrm{~km}$ northwest of Windsor (Figure 1(a)) and is subject to similar weather conditions. In 2005 , the annual average temperatures differed by $3 \%$ between the two cities and the relative humidity by $16 \%$ (with Sarnia experiencing higher humidity levels). The long-term (30 years) average wind speed is $16 \mathrm{~km} / \mathrm{h}$ in both cities. The wind is predominantly from the north and south for Sarnia and from the south and southwest for Windsor [6]. This means the two cities are comparable in terms of land use, climate, and geography.

Both study areas are known to experience poor air quality due in part to high VOC emissions. In Windsor, VOC emissions are likely attributable to the large number of manufacturing facilities and the high vehicle traffic emissions generated by the bridge crossing between Windsor, Ontario, and Detroit, Michigan. Sarnia has been labelled "Chemical Valley" due to the large number of chemical companies that operate in the area. Sarnia is also the location of a large sanitary landfill and has a major bridge crossing to the US with high vehicle volumes. These industrial and transportation activities are emitters of VOCs, specifically of BTEX.

To investigate how exposure to BTEX compounds can cause aberrant health effects, it is important to capture local-scale spatial variability, which cannot be accomplished with central monitoring stations such as those provided by the National Air Pollution Surveillance (NAPS) network [8]. Spatial variability of VOCs has been observed in several previous studies [1, 7, 9-11], where some factors (e.g., proximity to roads, industries, and wind direction) have been shown to influence their spatial distribution. In cities such as Windsor and Sarnia, point sources can exert a significant impact on residential exposure, as their concentration levels can show a strong spatial variability across the cities. For this reason, dense spatial networks are better suited to provide data at a resolution that may be linked with exposure and, ultimately, illness or disease. However, such dense networks are not always feasible due to the associated high cost of deployment and analysis. High costs also prohibit long-term, year-round sampling. Therefore, often one or several (across all seasons) short-term campaigns are used to estimate the spatial pattern of pollutants.

Recent studies have examined how the ratios between the BTEX species can provide insight into source origination as well as the photochemical age of the air mass. A specific range of the toluene to benzene ratio (T/B) has been used as an indicator of traffic emissions [11-14]. The values are in the range of 1.5-3.0 $[3,12,13,15,16]$, with variations likely attributable to different vehicle types and fuel composition in different regions. As pointed out by Gelencsér et al. [17], toluene and benzene concentrations are reduced through their reaction with $\mathrm{OH}$ radicals with the rate constant of toluene being approximately 5 times larger than that of benzene. Therefore, ambient T/B ratios that are significantly lower than vehicular emission ratios are expected to have travelled and degraded, whereas higher $\mathrm{T} / \mathrm{B}$ ratios may reflect relatively fresh vehicular emission sources. For example, this ratio was used to identify predominant hydrocarbon sources in 43 Chinese cities [13]. The B/T ratios of 10 cities were seen to be affected more by vehicular emissions as the main source of hydrocarbons. This was further confirmed by correlations between some traffic markers (benzene, toluene, and 1,3-butadiene) with ethyne and ethane, indicating the ability of T/B ratio to differentiate traffic emission dominated areas [14].

Due to the known rates of chemical reaction removal, the $(m+p)$-xylene to ethylbenzene $((m+p) / \mathrm{E})$ ratio can act as an indicator of the photochemical age of the air mass $[18,19]$. A ratio of $3.6: 1$ for $(m+p) / \mathrm{E}$ has been reported as the typical emission ratio for these species [18]. Studies have also identified a group of ratios that can indicate photochemical age. In addition to T/B and $(m+p) / \mathrm{E},(m+p)$-xylene to benzene 


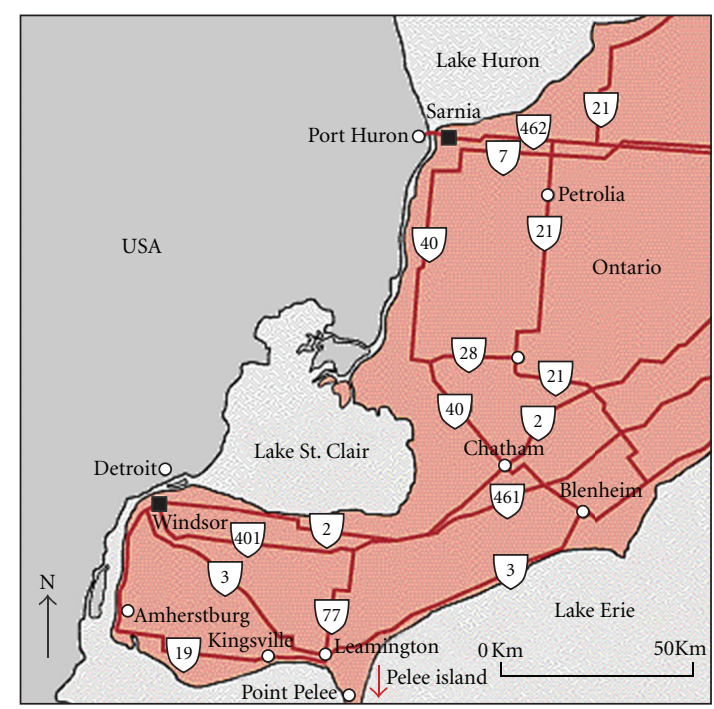

(a)

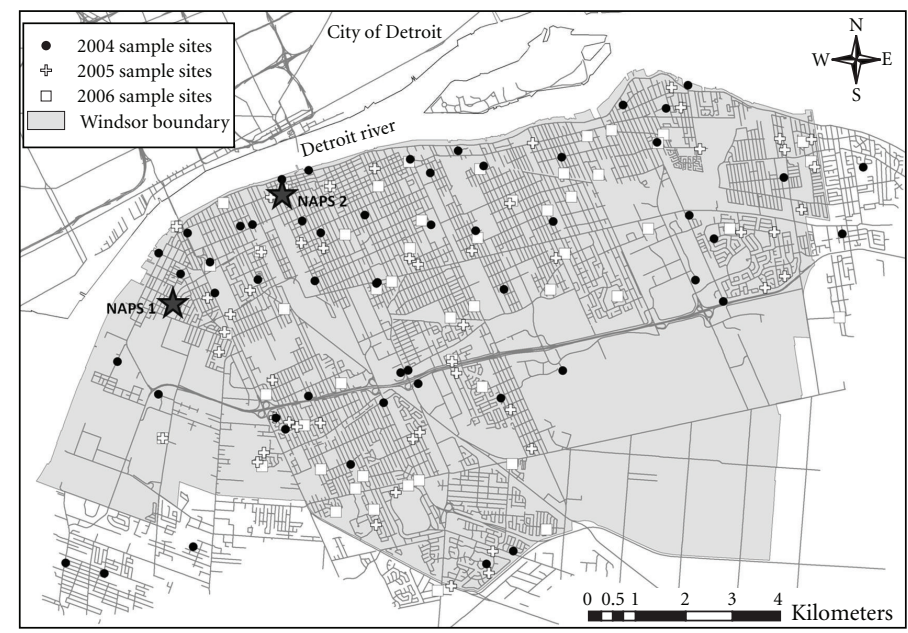

(b)

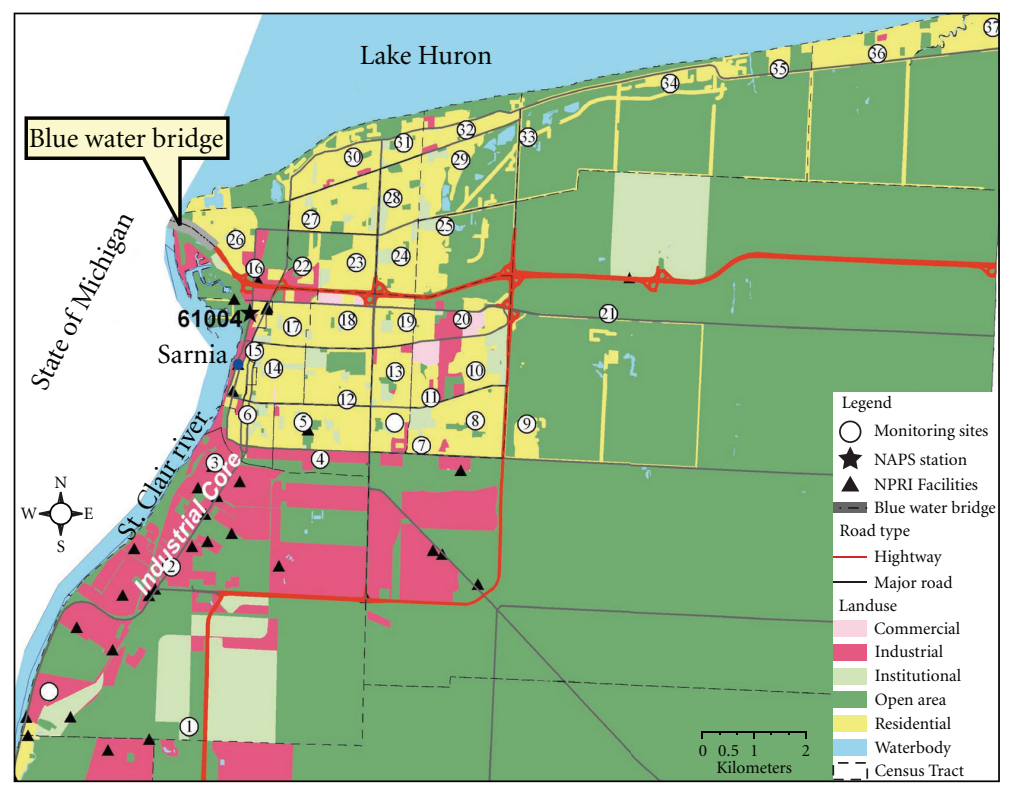

(c)

FIGURE 1: Maps of (a) study areas (http://ontournet.com/), (b) sampling locations and NAPS stations in Windsor, and (c) sampling locations, NAPS station, and land use in Sarnia (taken from [7]).

$((m+p) / \mathrm{B})$, and $o$-xylene to benzene $(\mathrm{O} / \mathrm{B})$ have also been used for such purpose [3, 12]. Higher values of these ratios (those closer to their expected emission ratio) typically indicate fresh local emissions, whereas lower values are associated with more photochemical degradation and therefore suggest that a sampling site is being influenced by emissions originated some distance away. Values of ratios reported as "high" in a previous study are as follows: $2.45(\mathrm{~T} / \mathrm{B}), 1.61(m+p) / \mathrm{B}, 0.85(\mathrm{O} / \mathrm{B})$, and $3.28(m+p) / \mathrm{E}$ [3]. Furthermore, $\mathrm{B}: \mathrm{T}: \mathrm{E}: \mathrm{X}$ ratios are useful for comparing sites across a city to identify areas influenced more strongly by one of the emission sources [3]. The degree to which the interspecies (I-S) ratios vary is also dependent on 
several factors including land use and climate, which are similar for the two cities that are the focus of this study.

This paper discusses synchronized VOC datasets from two cities to identify the factors that influence the BTEX concentrations and to characterize relationships between BTEX species. Additionally, this study investigates the use of specific ratios to estimate photochemical age and to differentiate different areas within a study area. Windsor and Sarnia were selected as they exhibit similar characteristics in terms of geographic location, weather patterns, degree of industrialization, and traffic. Furthermore, both cities had VOC data collected in the fall of 2005. The Sarnia BTEX data reported in this paper have previously been evaluated as part of a larger VOC dataset (10 species). It was shown that concentrations levels and patterns were strongly influenced by industrial sources [11]. In the current study, this analysis is expanded through comparison to another city (Windsor), consideration of interspecies ratios, and the impact of land use on these ratios.

\section{METHODS}

\subsection{Data Collection}

For Windsor, data were obtained for 27 VOCs for all four seasons (winter, spring, summer, and fall) over a three-year period (2004, 2005, and 2006) for a total of 12 sampling sessions. Sampling in Sarnia took place in the fall of 2005. In both cities, passive sampling was done using 3 M 3500 organic vapor samplers (Guillevan, Montreal, Quebec, Canada) at approximately the same sampling density (1 passive sampler per $5 \mathrm{~km}^{2}$ ). However, the sampling design differed for the two cities. In Sarnia, the 37 sampling locations (Figure 1) were selected to ensure that there was at least one site in or near every census tract and were more focused in residential areas than in industrial areas. In Windsor, locations were selected based on approximately even spatial distribution over the city, while also considering population density, with 52 sites in 2005 and 162 sites over the three years. Samplers were installed on light poles (in Windsor in 2004 and in Sarnia in 2005) or in residential backyards (Windsor 2005-2006) with shelters to protect them from inclement weather. Each sampling campaign was a 2-week integrated period. The fall 2005 sampling took place from October 4 to 18 in Sarnia and from October 5 to 19 in Windsor. The laboratory analysis of samples was conducted at the same facility (Airzone One, Mississauga, ON, Canada). Details of laboratory analyses and data screening have been previously documented in $[7,20]$. Benzene, toluene, ethylbenzene, $o$-xylene, and $(m+p)$-xylene concentrations were used in this study. Samples with any of the five concentrations below the method detection limit were excluded, since the I-S ratios would not be representative.

\subsection{Data Analysis}

Statistical analyses were conducted in each city using Minitab Version 16. Pearson's correlation coefficients between benzene and TEX were obtained. The rank (i.e., highest to lowest) order of concentrations and correlations was also determined. The I-S ratios relative to benzene, the $\mathrm{B}: \mathrm{T}: \mathrm{E}: \mathrm{X}$ ratio, and $(m+p) / \mathrm{E}$ ratio were calculated using fall 2005 data as well as three years of fall data from Windsor. These ratios were further examined to determine if they could differentiate different areas within Sarnia. Furthermore, land use variables, including distance to open and industrial areas as well as length of highway and dwelling counts, were used to investigate any associations with the concentration ratios in Sarnia. The land use variables were generated within circular buffers that extended from the sampling locations. The set of variables used in correlation analysis were selected as the predictors having significant correlation with BTEX concentrations and low collinearity with other predictor variables. More information on the generation and selection of those variables can be found in [21]. Finally, the same sets of ratios were calculated based on emissions reported to the National Pollutant Release Inventory (NPRI) [22], as well as based on the concentrations reported by the NAPS stations [8]. 
TABLE 1: Mean fall concentration values and standard deviation (in parenthesis) in Windsor and Sarnia $\left(\mu \mathrm{g} / \mathrm{m}^{3}\right)$.

\begin{tabular}{lcccccc}
\hline & Benzene & Toluene & Ethylbenzene & $(m+p)$-xylene & $o$-xylene & BTEX \\
\hline Windsor 3 yrs fall $(N=144)$ & $0.79(0.38)$ & $2.87(1.92)$ & $0.49(0.24)$ & $1.54(0.91)$ & $0.53(0.31)$ & $6.12(3.21)$ \\
Windsor fall 2005 $(N=42)$ & $0.76(0.14)$ & $2.87(1.13)$ & $0.47(0.21)$ & $1.33(0.76)$ & $0.47(0.18)$ & $5.89(1.93)$ \\
Sarnia fall 2005 $(N=37)$ & $0.98(0.54)$ & $2.51(1.31)$ & $0.48(0.22)$ & $1.28(0.59)$ & $0.49(0.24)$ & $5.73(2.78)$ \\
\hline
\end{tabular}

TABLE 2: Pearson's correlation coefficients between benzene and TEX in Windsor and Sarnia (all significant at $P<0.05)$.

\begin{tabular}{lcccc}
\hline & Toluene & Ethylbenzene & $(m+p)$-xylene & $o$-xylene \\
\hline Windsor 2004-2006 fall & 0.75 & 0.67 & 0.63 & 0.68 \\
average $(N=144)$ & 0.67 & 0.72 & 0.69 & 0.72 \\
Windsor fall 2005 $(N=42)$ & 0.85 & 0.81 & 0.66 & 0.67 \\
Sarnia fall 2005 $(N=37)$ & &
\end{tabular}

\section{RESULTS AND DISCUSSION}

\subsection{Concentrations}

Pollutant concentrations, including descriptive statistics, have been reported elsewhere (for Sarnia [7], and will be reported elsewhere, for Windsor). The average fall concentrations for both cities are reported in Table 1. The concentration ranking was the same for each city with toluene being the highest and ethylbenzene the lowest, which is also consistent with a 2006 study in the nearby city of Detroit, MI, USA [23]. In Windsor, the fall 2005 values were similar to the 3-year average fall values, indicating that fall 2005 was representative of typical seasonal concentrations. The mean values for each species were similar between the two cities, the differences varying from $22 \%$ (benzene) and $14 \%$ (toluene) to less than 5\% for other BTEX concentrations (ethylbenzene, xylenes, and total BTEX).

\subsection{Interspecies Correlations}

The I-S correlations with benzene for the fall season in both cities are presented in Table 2. Strong correlations ranging from 0.63 to 0.85 were observed between benzene and TEX in both cities. This is consistent with previous studies in urban areas [1, 3, 7, 11, 12, 24, 25]. The correlation coefficient observed between benzene and toluene in Sarnia was slightly higher ( 0.85 versus 0.67 in Windsor), which indicates that these pollutants likely originate from common sources. Investigation into which sources were high emitters in each city revealed that the manufacturing and industrial activities differed. In Windsor, the major VOC emitters were automotive manufacturing and supplier facilities, tool, mould, and metal stamping facilities, and paint manufacturing. In Sarnia, oil refineries and large chemical companies were the major emitters. Despite the different activities, both cities were highly industrialized at the time of sampling and the types of VOCs being emitted were similar for their industries. Overall, the correlations support the conclusion that, in both cities, the emissions from this group of VOCs can be attributed to their respective industrial and mobile emissions.

\subsection{Interspecies Ratios in Both Cities}

The means and medians of four specific interspecies ratios, T/B, $(m+p) / \mathrm{B}, \mathrm{O} / \mathrm{B}$, and $(m+p) / \mathrm{E}$, averaged over all sites for each city are presented in Table 3. Those ratios are commonly used as indicators of 
TABLE 3: Mean, median, and coefficient of variation (CV) of interspecies ratios in Windsor and Sarnia.

\begin{tabular}{lcccccc}
\hline & & T/B & E/B & $(m+p) / \mathrm{B}$ & $\mathrm{O} / \mathrm{B}$ & $(m+p) / \mathrm{E}$ \\
\hline \multirow{3}{*}{ Windsor 3 years fall $(N=144)$} & Mean & 3.91 & 0.59 & 2.02 & 0.68 & 3.03 \\
& Median & 3.42 & 0.60 & 1.90 & 0.61 & 2.86 \\
& CV $(\%)$ & 30 & 22 & 25 & 28 & 22 \\
\hline \multirow{3}{*}{ Windsor fall 2005 $(N=42)$} & Mean & 3.72 & 0.58 & 1.60 & 0.59 & 2.76 \\
& Median & 3.44 & 0.59 & 1.65 & 0.60 & 2.77 \\
& CV $(\%)$ & 31 & 21 & 21 & 21 & 7 \\
\hline \multirow{3}{*}{ Sarnia fall 2005 $(N=37)$} & Mean & 2.92 & 0.52 & 1.40 & 0.56 & 2.63 \\
& Median & 2.89 & 0.52 & 1.38 & 0.55 & 2.70 \\
& CV $(\%)$ & 27 & 28 & 33 & 33 & 9 \\
\hline
\end{tabular}

photochemical age or predominant emission sources. The intracity variability was low for all ratios in Windsor and for all except T/B in Sarnia, with less than $25 \%$ of the sites falling outside of the range of the mean value \pm 1 standard deviation. For the T/B ratio in Sarnia, up to $38 \%$ of sites fell beyond the same range, indicating the impact of numerous point sources of benzene and toluene ( 8 and 12 facilities, respectively, [22]).

The mean ratios were similar in the two cities with the exception of $\mathrm{T} / \mathrm{B}$, which was significantly higher in Windsor (3.72 versus 2.92 in Sarnia), indicating higher local emissions of toluene. The mean T/B ratio in Sarnia was in the upper range of 1.5-3.0, which is indicative of strong contributions from mobile sources [3, 12]. In Windsor, the mean T/B ratios were outside of this range (3.7 for fall 2005 and 3.9 for fall 2004, 2005, and 2006), indicating that industrial activities were also large contributors to toluene. The high T/B ratios observed in Windsor are consistent with results reported for fall 2008 [11]. The mean ratio of 4.3 observed in 2008 was well outside of the traffic range (1.5-3.0) and higher than that observed in this study (3.7), further confirming the influence of point sources of toluene in Windsor.

As with the concentrations, the rank order of the I-S ratios remained the same in both cities. The citywide mean ratios were also similar for fall 2005, although less so for the T/B ratios which differed by $32 \%$. The higher ratios in Windsor can be linked to higher reported emissions from the NPRI [22]. For Windsor, 180 tonnes of toluene were emitted in 2005 with no reported benzene emissions, whereas, for Sarnia, 86 tonnes of toluene were reported and 52 tonnes of benzene. This observation gives insight as to why the T/B ratios were higher in Windsor, benzene was emitted by vehicular sources, and toluene was released from both mobile and point sources. This also explains the lower correlation between benzene and toluene in Windsor since different sources are emitting these species.

The emission ratios were not indicative of the concentration ratios. For example, in Windsor the T/B ratio would be extremely high (estimated at 180/1) due to having zero reported point source emissions of benzene, indicating that benzene is originating from sources other than industry in Windsor. In Sarnia, the T/B emission ratio was much lower (1.65) than the mean concentration ratio (2.92). In the $\mathrm{B}: \mathrm{T}: \mathrm{E}: \mathrm{X}$ ratios for both cities (Table 4), toluene was in higher concentration ratios than would normally be attributable to traffic emissions $(3: 4: 1: 4)$ [15]. However, toluene is not high in the $\mathrm{B}: \mathrm{T}: \mathrm{E}: \mathrm{X}$ emission ratios $(0: 2.3: 1: 1.3$ for Windsor and $1.7: 2.6: 1: 2.1$ for Sarnia). Differences in emissions of the other species such as higher ethylbenzene and xylenes in Windsor were not reflected in the concentrations (Table 1) or ratios (Table 3). However, it is difficult to decipher since the NPRI reports all xylene isomers into one category. Overall, low agreement was seen between the emission and concentration ratios, which can be expected since the emission ratios did not account for photochemical age and did not include mobile source emissions.

The four concentration ratios $(\mathrm{T} / \mathrm{B},(m+p) / \mathrm{B}, \mathrm{O} / \mathrm{B}$, and $(m+p) / \mathrm{E})$ were in agreement with one another in Sarnia. If one of these ratios was low (lowest quartile) or high (highest quartile), the chances of 
TABLE 4: B: T:E : X ratios in Windsor, Sarnia, and the previous literature.

\begin{tabular}{lcc}
\hline & Site & B : T:E:X \\
\hline Windsor & $N=42$ & $1.80: 6.47: 1: 3.77$ \\
Sarnia & $N=37$ & $2.05: 5.58: 1: 3.68$ \\
& Site 1 (urban) & $2.01: 4.94: 1: 4.95$ \\
Greater Cairo [3] & Site 2 (urban) & $2.03: 4.91: 1: 4.87$ \\
& Site 3 (rural) & $2.31: 2.98: 1: 2.59$ \\
China [26] & City of Guangzhou & $2.9: 4.3: 1: 4.6$ \\
Taiwan-vehicle exhaust [15] & Tunnel & $3: 4: 1: 4$ \\
\hline
\end{tabular}

at least two of the other ratios being in the same quartile were $89 \%$ and $100 \%$, respectively. The agreement in Windsor between the ratios was not as high: $50 \%$ for low sites, and $40 \%$ for high sites, with the T/B ratio being responsible for the majority of the discrepancies. This is likely due to the quantity or location of point source emissions of toluene or influences from transboundary pollution.

The mean B : T : E : X ratios were also calculated and compared with other studies (Table 4). Sarnia compares well with the two urban sites in Greater Cairo and sites in China, although toluene is higher for Sarnia and the xylenes are lower. For Windsor, toluene is even higher, although the other ratios are comparable to the previous studies. Compared with the ratios obtained in Taiwan, which are indicative of vehicle emissions, it is clear that there are other activities in Windsor and Sarnia contributing to the BTEX emissions, particularly toluene.

Pearson's correlations between the ratios in each city also shed light on how different emissions affect the ratios. Although all ratios were significantly correlated $(0.510<r<0.996, P<0.05)$ in both cities, the T/B, O/B, and $(m+p) / \mathrm{B}$ were more highly correlated in Sarnia $(r>0.943)$, indicating that these are likely governed by benzene emissions. Low correlations between T/B and other ratios in Windsor $(0.510<r<0.585)$ suggest that toluene emissions govern the T/B ratios. Correlations between $(m+p) / \mathrm{B}$, $\mathrm{O} / \mathrm{B}$, and $(m+p) / \mathrm{E}$ were similar in both cities.

\subsection{Intracity Variability of Relationships between the BTEX Species within Sarnia}

Unlike Windsor, the majority of emitting facilities in Sarnia are located in a distinct industrial core (Figure 1(c)) that is separated from residential areas. The sites that were commonly identified as having high and low photochemical age ratios $(\mathrm{T} / \mathrm{B},(m+p) / \mathrm{B}, \mathrm{O} / \mathrm{B},(m+p) / \mathrm{E})$ in Sarnia are identified in Table 5. As indicated in Figure 1, the high-ratio sites were within the residential area, whereas most of the low-ratio sites were found in areas away from the residential area. This finding is consistent with that in [3] where maximum $\mathrm{T} / \mathrm{B},(m+p) / \mathrm{B}$, and $\mathrm{O} / \mathrm{B}$ ratios were observed in high traffic areas and lower ratios in areas less influenced by traffic.

Further examination of these ratios in Sarnia illustrates the ability of these ratios to differentiate areas within a city. There appear to be two areas where lower ratios were observed, within the industrial core (Group A: industry) and in the area near Lake Huron (Group B: clean). The reasons for these two low-ratio areas are different. Near the industrial core (sites 1,2,3), benzene concentrations were higher (ranked 1, 4, and 5), and therefore the $\mathrm{T} / \mathrm{B}, \mathrm{O} / \mathrm{B}$, and $(m+p) / \mathrm{B}$ ratios were lower. In the area near Lake Huron (sites 34, 35, 36, 37), the low ratios were due to low-concentration values of all species (less than half of the mean values for TEX and approximately two-thirds the mean value for benzene). This is an important finding with respect to how BTEX ratios can be used in cities with fresh industrial emissions. Although both groups of sites were in areas less influenced by traffic, the reason for the low-ratio values is not the same. This should be considered when attempting to group sites by photochemical age through reliance on these ratios. One difference is in the $(m+p) / E$ ratio, which is less consistent amongst the low ratios in the 
TABLE 5: High- and low-ratio sites in Sarnia and characterization of pollutant mixtures.

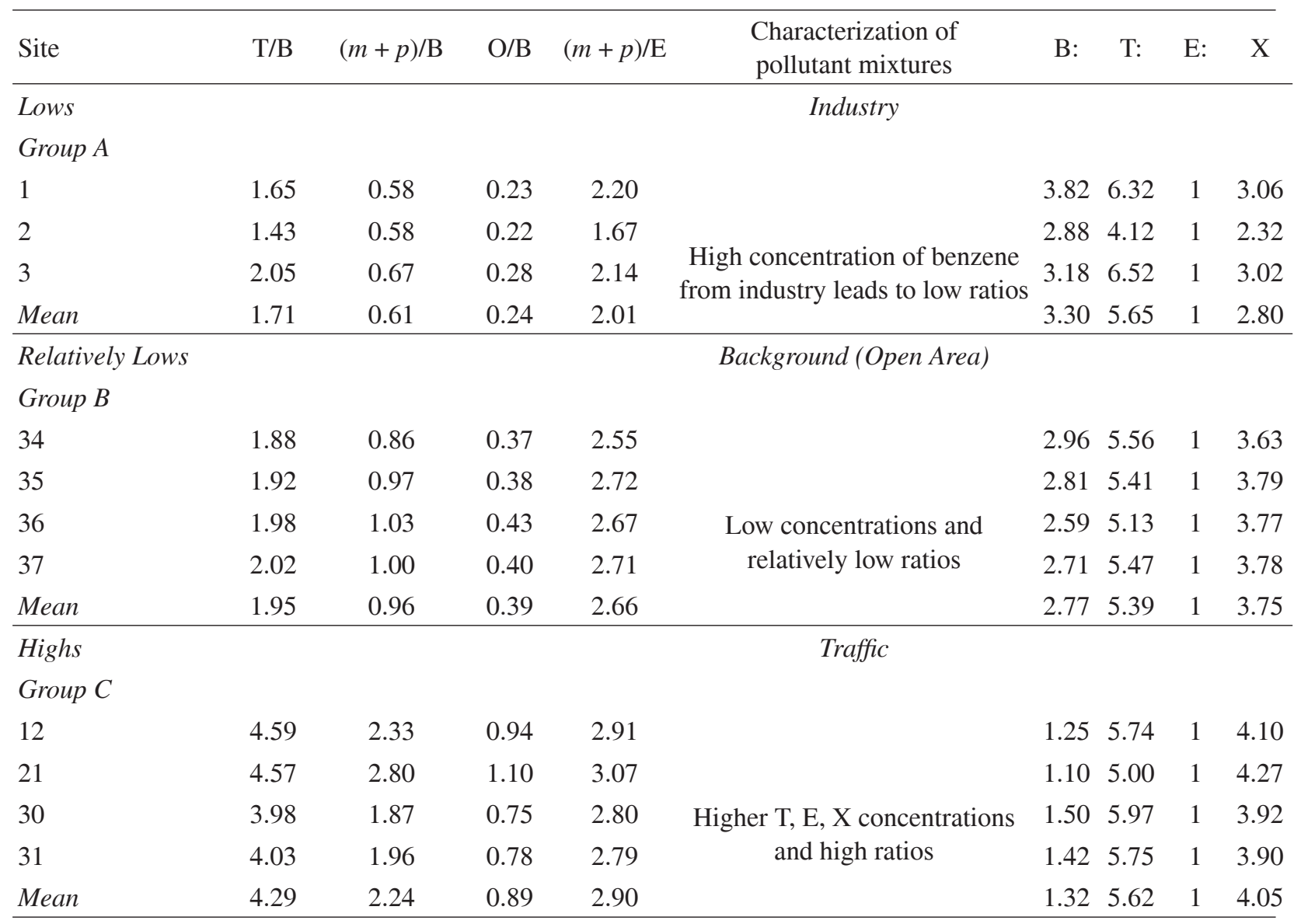

industrial core but more consistent amongst the low ratios experienced near Lake Huron. This suggests that the ratios at the sites near the lake were truly indicative of photochemical age-lower ratios due to dispersion and degradation of pollutants as they reached this area. On the other hand, the ratios obtained at the sites in the industrial core may not actually be related to photochemical age but more related to the quantities of emissions at nearby point sources. Therefore, the simple use of these ratios to indicate photochemical age may only be appropriate in areas away from point sources which may bias the ratios. In areas with significant point sources, this analysis may become more complex and could be broken down into more categories, for examples, low concentration/low ratios indicative of regional background influence and high concentration/low ratios indicative of fresh sources.

As for the high photochemical age ratios (Group C: traffic), these were all found in the residential area and could be attributed to traffic. Sites 12, 21, 30, and 31 were high for all four ratios, whereas these, plus sites $4,5,7,8,12,14,22,23$, and 28 , were high for the $\mathrm{T} / \mathrm{B}, \mathrm{O} / \mathrm{B}$, and $(m+p) / \mathrm{B}$. Since these sites were located near highways or major roads, the higher ratios were likely due to fresh traffic emissions. Even though some distinct differences were seen in the ratios in the different areas (industrial, clean, traffic), these differences were small. Higher variability in the ratios is likely when larger areas with different land uses are considered, as was the case in Greater Cairo [3]. Significant differences were observed between the high- and low-ratios relative to benzene, however, this difference was small for $(m+p) / \mathrm{E}$. The differences between the two low-ratio groups were small, especially for T/B, indicating the importance of considering all ratios when making conclusions about their relevance. Looking at one ratio in isolation may lead to false conclusions regarding photochemical age and emission source origins. 
TABLE 6: Pearson's correlation coefficients between pollutant ratios and land use variables.

\begin{tabular}{|c|c|c|c|c|c|c|c|c|}
\hline \multirow{2}{*}{ Land use variables } & \multicolumn{7}{|c|}{ Pollution ratios } & \multirow[b]{2}{*}{$\mathrm{O} / \mathrm{B}$} \\
\hline & $\mathrm{B} / \mathrm{E}$ & $\mathrm{T} / \mathrm{E}$ & $(m+p) / \mathrm{E}$ & $\mathrm{O} / \mathrm{E}$ & $\mathrm{X} / \mathrm{E}$ & $\mathrm{T} / \mathrm{B}$ & $(m+p) / \mathrm{B}$ & \\
\hline $\begin{array}{l}\text { Open Area within } \\
600 \mathrm{~m}\end{array}$ & 0.173 & -0.089 & 0.108 & 0.014 & 0.081 & -0.064 & 0.048 & 0.021 \\
\hline $\begin{array}{l}\text { Industrial Area within } \\
1600 \mathrm{~m}\end{array}$ & 0.262 & 0.017 & $-0.614^{* * *}$ & $-0.512^{* * *}$ & $-0.591^{* * *}$ & -0.210 & $-0.289^{*}$ & -0.265 \\
\hline $\begin{array}{l}\text { Industrial Area within } \\
2500 \mathrm{~m}\end{array}$ & 0.137 & -0.093 & $-0.453^{* * *}$ & $-0.374^{* *}$ & $-0.435^{* * *}$ & -0.097 & -0.128 & -0.104 \\
\hline $\begin{array}{l}\text { Industrial Area within } \\
2800 \mathrm{~m}\end{array}$ & 0.102 & -0.089 & $-0.403^{* *}$ & $-0.319^{*}$ & $-\mathbf{0 . 3 8 3}^{* *}$ & -0.064 & -0.091 & -0.064 \\
\hline $\begin{array}{l}\text { Length of Highway } \\
\text { within } 800 \mathrm{~m}\end{array}$ & 0.014 & 0.150 & 0.008 & -0.057 & -0.012 & -0.008 & -0.030 & -0.049 \\
\hline $\begin{array}{l}\text { Length of Highway } \\
\text { within } 900 \mathrm{~m}\end{array}$ & -0.009 & 0.126 & 0.030 & -0.040 & 0.009 & 0.003 & -0.006 & -0.027 \\
\hline $\begin{array}{l}\text { Dwelling Counts } \\
\text { within } 1200 \mathrm{~m}\end{array}$ & $-0.407^{* *}$ & 0.000 & $0.341^{* *}$ & $\mathbf{0 . 3 8 3}^{* *}$ & $\mathbf{0 . 3 5 8}^{* *}$ & 0.265 & 0.261 & $0.284^{*}$ \\
\hline $\begin{array}{l}\text { Dwelling Counts } \\
\text { within } 1400 \mathrm{~m}\end{array}$ & $-0.330^{* *}$ & $0.277^{*}$ & 0.273 & $0.329^{* *}$ & $0^{293}{ }^{*}$ & $0.281^{*}$ & 0.184 & 0.204 \\
\hline
\end{tabular}

*** Significant at $P<0.01 ;{ }^{* *}$ Significant at $P<0.05 ;{ }^{*}$ Significant at $P<0.10$.

Table 5 also shows the $\mathrm{B}: \mathrm{T}: \mathrm{E}: \mathrm{X}$ ratios at the low and high photochemical ratio sites. The T/E ratios showed little variation amongst the three areas. The values were greater than 4 , which was reported to be indicative of traffic [15], suggesting toluene emissions from point sources. Furthermore, lower T/E ratio at the rural site as reported in [3] was not observed at these sites, indicating once again toluene emissions from non traffic sources. Higher X/E and E/B ratios were observed in the traffic area (Group C) and lower ratios in the industrial area (Group B). The B/E pattern is consistent with [3]. The low X/E ratio in the industrial area is due to low concentrations of xylenes, which may be predominantly emitted from vehicles and not point sources in this city.

In summary, relatively low $\mathrm{T} / \mathrm{B},(m+p) / \mathrm{B}, \mathrm{O} / \mathrm{B}, \mathrm{E} / \mathrm{B}$, and $(m+p) / \mathrm{E}$ ratios were observed in the clean areas, and the high ratios were observed in the traffic areas. However, low ratios were observed in the industrial areas. When considering these ratios, concentration levels, proximity to known sources, and correlations between species should be taken into consideration when determining whether the air pollutants are aged or freshly emitted.

Land use variables were investigated to determine whether any of these were correlated with the concentration ratios in Sarnia. The land use variables selected are listed in Table 6. Significant correlations were observed between several of the B : T:E : X ratios and proximity to industry, specifically the xylenes to ethylbenzene ratios. The negative correlations indicate more industrial land use leading to lower X/E ratios, consistent with results presented in Table 5. The correlation becomes weaker with increasing buffer radian, suggesting diminishing effects of industrial emissions on the observed concentration ratios. Furthermore, positive correlation between the $\mathrm{X} / \mathrm{E}$ ratio and dwelling counts indicates that this ratio is able to distinguish between residential and industrial areas. The $(m+p) / \mathrm{B}$ ratio was also marginally negatively correlated with industrial land use within $1600 \mathrm{~m}$, but not so for greater distances.

Significant positive correlations were observed between the B:T:E:X ratios and dwelling counts within 1200 and $1400 \mathrm{~m}$, with the exception of $\mathrm{B} / \mathrm{E}$ where negative correlations were observed. These correlations are likely attributable to local traffic in these residential areas. Significant correlations were not observed between any of the ratios and open areas or length of highway. This may be due to the small study area used to obtain the ratios. There is not as much variability in the age of the air masses as would be 
expected in a larger city or region. Overall, the correlations with the land use variables confirms that these ratios change depending on location within a city and can indeed be indicative of the activities or land use types nearby. Future research in larger areas is needed to further explore the utility of these ratios and their association with land use.

\subsection{Interspecies Ratios at the NAPS Stations}

In both cities there is one NAPS station (NAPS 1 for Windsor, shown in Figure 1(b)) to sample VOCs approximately once every six days [8]. Previously, NAPS concentrations have been reported to be representative of concentrations averaged across citywide monitors in Sarnia [7]. However, small differences in concentrations could lead to large differences in ratios. Therefore, the NAPS station may not represent city-wide average ratios well. Furthermore, there could be significant differences in ratios between each site and the NAPS station.

In Sarnia, there were four dates when sampling data was available around the same time as the monitoring campaign in this study: October 1, 7, 19, and 25, 2005. Ratios from concentrations reported on these individual dates, as well as those averaged over all four dates, are provided in Table 7. Among the five ratios, the three ratios involving benzene were significantly different than the average ratios from the 37 monitors across the city. On the contrary, the $(m+p) / \mathrm{E}$ and $\mathrm{B}: \mathrm{T}: \mathrm{E}: \mathrm{X}$ ratios were similar to that of the city-wide averages. In addition, the median percent differences between the four-day NAPS average photochemical ratios and those obtained at each of the sites across the monitoring campaign ranged from $22 \%((m+p) / \mathrm{E})$ to $139 \%(\mathrm{O} / \mathrm{B})$, with the positive values indicating that the NAPS ratios were lower than most ratios obtained from the spatial campaign. The percent differences indicate significant variability between the two sets of ratios, but more for some ratios than others. This is also evidenced by the percent differences up to $377 \%(\mathrm{O} / \mathrm{B})$. The ratios on the four separate dates were fairly consistent, suggesting that the monitoring site does a reasonable job of determining the relationship between the species in that one specific area. However, it is not applicable across the city. Further investigation examined the three sites (Sites 15-17, Figure 1(c)) that were closest to the NAPS station. The ratios from these sites were significantly different from those obtained at the NAPS site, with percent differences ranging from 15 to $117 \%$, suggesting that differing sampling methodology and frequency of measurements were likely some of the causes for the discrepancy. The ratios from these nearby sites fell in between the high- and low-ratio groups (Table 5) and were very similar to the city-wide means (Tables 3 and 5), differing by less than 13\% for all ratios. The reason for these ratios falling in between the high and low ratios was likely due to this area being influenced by traffic and, to a lesser degree, by industry as well as their locations along the St. Clair River.

In Windsor, data from the NAPS station was available for only one sampling date around the time of the monitoring campaign: October 25, 2005. With the exception of T/B, these were similar to those mean values obtained from the spatial monitoring campaign. In both cities, the $(m+p)$ /E ratios exhibited the least deviation from the single NAPS station, indicating relatively uniform photochemical aging across each city. T/B ratios observed at NAPS were poor indicators in both cities due to point source emissions. Large differences were observed between NAPS and the spatial network $(m+p) / \mathrm{B}$ and $\mathrm{O} / \mathrm{B}$ ratios in Sarnia, with relatively small differences observed in Windsor. This is due to the presence of numerous stationary benzene sources in Sarnia, whereas there are no point sources in Windsor. The maximum percent differences between the NAPS T/B, $(m+p) / \mathrm{B}, \mathrm{O} / \mathrm{B},(m+p) / \mathrm{E}$ ratios and those obtained from the 42 Winsor sites ranged from $-57 \%(\mathrm{O} / \mathrm{B})$ to $163 \%(\mathrm{~T} / \mathrm{B})$. These differences are less than those observed in Sarnia. For Sarnia, the one central station was located in a residential area near the international bridge, which did not capture the high and low ratios due to being some distance away from the industrial and open areas. In Windsor, it seems that the central station did a better job representing the concentration ratios across the city, possibly due to the fact that the industrial sites were spread across the city rather than situated in a concentrated area. Due to the limitation of having only one day of NAPS data for the sampling period in Windsor, future work should consider these comparisons over a longer timeframe. 
TABLE 7: Ratios calculated using three nearby monitoring sites in Sarnia and NAPS data in Sarnia and Windsor.

\begin{tabular}{|c|c|c|c|c|c|}
\hline & $\mathrm{T} / \mathrm{B}$ & $(m+p) / \mathrm{B}$ & $\mathrm{O} / \mathrm{B}$ & $(m+p) / \mathrm{E}$ & $\mathrm{B}: \mathrm{T}: \mathrm{E}: \mathrm{X}$ \\
\hline \multicolumn{6}{|l|}{ Sarnia } \\
\hline NAPS October 1 & 1.92 & 0.78 & 0.23 & 2.22 & $2.86: 5.50: 1: 2.88$ \\
\hline NAPS October 7 & 1.82 & 0.76 & 0.29 & 2.60 & $3.40: 6.20: 1: 3.6$ \\
\hline NAPS October 19 & 1.80 & 0.45 & 0.15 & 1.40 & $3.11: 5.59: 1: 1.88$ \\
\hline NAPS October 25 & 1.67 & 0.74 & 0.26 & 2.63 & $3.55: 5.94: 1: 3.54$ \\
\hline $\begin{array}{l}\text { October } 1,7, \& 19,25 \\
\text { mean }\end{array}$ & 1.80 & 0.68 & 0.23 & 2.21 & $3.23: 5.81: 1: 2.98$ \\
\hline Site 15 & 3.21 & 1.43 & 0.57 & 2.59 & $1.87: 5.83: 1: 3.62$ \\
\hline Site 16 & 2.53 & 1.00 & 0.41 & 2.42 & $2.42: 6.11: 1: 3.42$ \\
\hline Site 17 & 2.74 & 1.30 & 0.53 & 2.62 & $2.01: 5.51: 1: 3.68$ \\
\hline 3 nearby sites mean & 2.83 & 1.24 & 0.50 & 2.54 & $2.10: 5.82: 1: 3.57$ \\
\hline \multicolumn{6}{|l|}{$\%$ Difference between } \\
\hline \multicolumn{6}{|l|}{ NAPS and 37 sites } \\
\hline Median & 60.4 & 102 & 139 & 22.0 & \\
\hline Min & -20.7 & -15.2 & -2.56 & -24.5 & \\
\hline Max & 154 & 312 & 377 & 39.0 & \\
\hline \multicolumn{6}{|l|}{ Windsor } \\
\hline NAPS October 25 & 2.60 & 1.88 & 0.53 & 3.00 & $1.59: 4.15: 1: 3.85$ \\
\hline \multicolumn{6}{|l|}{$\%$ Difference between } \\
\hline \multicolumn{6}{|l|}{ NAPS and 42 sites } \\
\hline Median & 32.4 & -0.26 & 12.5 & -7.64 & \\
\hline Min & -45.3 & -1.50 & -56.9 & -40.2 & \\
\hline Max & 163 & 0.82 & 78.4 & 3.07 & \\
\hline
\end{tabular}

\section{CONCLUSIONS}

The overall rank order and values of the BTEX concentrations, correlations, and ratios were found to be similar in two southwestern Ontario cities, Windsor and Sarnia. However, some significant differences were noted, leading to the determination of predominant sources in each city. With the exception of vehicular emissions, the sources of BTEX differed between the two cities. Windsor was highly influenced by automotive manufacturing activities while Sarnia was mainly exposed to emissions from petroleum processing sources. Since Windsor borders Detroit and Sarnia borders Port Huron, both cities may have been influenced by transboundary pollution. Despite these differences, the I-S ratios relative to benzene and ethylbenzene were found to be similar for both cities, suggesting that BTEX species were emitted in relatively set ratios, regardless of the nature of industrial activities. Whether this is true in other regions with different industries should be explored in future studies.

The interspecies ratios suggest fresh mobile sources as in previous urban studies, although both cities had significant nonvehicular air emissions of BTEX. This study led to new findings. First, the interspecies concentration ratios were successfully used to identify contributions of point source emissions in both cities. The B : T : E : X ratios indicate higher toluene emissions in Sarnia and Windsor. In Sarnia, large variability was observed in the T/B ratios, indicating large contributions of these two compounds from point sources. The four photochemical age ratios $(\mathrm{T} / \mathrm{B},(m+p) / \mathrm{B}, \mathrm{O} / \mathrm{B}$, and $(m+p) / \mathrm{E})$ were found to be in better agreement 
with each other in Sarnia than in Windsor. In Windsor, the T/B ratio did not agree as well with the other ratios. Also, the mean T/B ratio was found to be higher and outside the range normally indicative of traffic. Furthermore, lower correlations between T/B and the other photochemical age ratios and between toluene concentrations and other species were observed in Windsor. All of these results suggest that there were significant emissions of toluene and benzene from nonvehicular sources in Windsor and Sarnia, respectively, which was confirmed by consulting the NPRI reporting.

Second, the quantity of point source air emissions, that means, higher benzene in Sarnia and more toluene in Windsor, was consistent with the higher benzene concentrations in Sarnia and higher toluene concentrations in Windsor. However, the emission ratios were not in agreement with the concentration ratios found in either city nor indicative of the difference in concentration ratios between the two cities. Future studies could make accurate estimates of BTEX emissions from vehicular sources in these areas, thus making it possible to compare emission profiles of, and properly apportion of, the relative contributions from mobile and point sources, respectively.

Third, it was observed that specific ratios representing photochemical age varied significantly for the different areas in Sarnia. These ratios could differentiate between clean, traffic, and industrial areas in Sarnia (however, the differences were small due to the relatively small study area). When using these ratios, caution is needed to ensure that they are not being biased by nearby point source emissions. Considering all ratios together leads to better conclusions regarding photochemical aging of these pollutants within the city. In addition, these ratios can be low or high for different reasons, either due to true photochemical aging or due to close proximity of emissions. In Sarnia, proximity to industry was the most significant influence on the $\mathrm{X} / \mathrm{E}$ ratios, whereas $\mathrm{B}: \mathrm{T}: \mathrm{E}: \mathrm{X}$ was also associated with dwelling counts.

Last, the reliance on central monitoring stations likely leads to misclassification of exposure assessment and emission source identification and more where there is a greater number of point sources concentrated in one area far removed from a central monitoring station. This was evidenced by less agreement between the NAPS ratios and the spatial monitoring campaign ratios in Sarnia than those in Windsor. Also, in Sarnia the NAPS ratios were not able to differentiate areas of the city by land use in the way that the sampling campaign ratios might.

The insights gained may benefit future air quality spatial analyses and epidemiological studies. Despite the challenges, the use of ratios to identify photochemical aging and potential source origination is promising. However, the applications of these ratios may not be as simple as claimed in previous studies. These ratios will work differently depending on their area of application and consideration must be given to nearby sources.

\section{ACKNOWLEDGMENTS}

The authors wish to thank the study participants for allowing access to their properties for locating sampling equipment, James Brown at Enwin Utilities in Windsor, the City of Sarnia and the Aamjiwnaang Indian Reserve for permissions to place samplers on light poles, Jeffrey Brook at Environment Canada for his invaluable contributions to the design and execution of the Windsor field study, Tom Dann, Dennis Herod, and Daniel Wang at Environment Canada for providing the NAPS VOC data, Health Canada researchers Hongyu You, Ryan Kulka, Keith Van Ryswyk, Corrine Stocco, and Angelos Anastassopoulos, and University of Windsor students for field work. Funding for this project was provided by Health Canada, the Social Sciences and Humanities Research Council of Canada, and the National Science and Engineering Research Council of Canada.

\section{REFERENCES}

[1] M. A. Parra, L. González, D. Elustondo, J. Garrigó, R. Bermejo, and J. M. Santamaría, "Spatial and temporal trends of volatile organic compounds (VOC) in a rural area of northern Spain," Science of the Total Environment, vol. 370, no. 1, pp. 157-167, 2006. 
[2] S. N. Sax, D. H. Bennett, S. N. Chillrud, J. Ross, P. L. Kinney, and J. D. Spengler, "A cancer risk assessment of inner-city teenagers living in New York City and Los Angeles," Environmental Health Perspectives, vol. 114, no. 10, pp. 1558-1566, 2006.

[3] M. I. Khoder, "Ambient levels of volatile organic compounds in the atmosphere of Greater Cairo," Atmospheric Environment, vol. 41, no. 3, pp. 554-566, 2007.

[4] K. W. Whitworth, E. Symanski, and A. L. Coker, "Childhood lymphohematopoietic cancer incidence and hazardous air pollutants in Southeast Texas, 1995-2004," Environmental Health Perspectives, vol. 116, no. 11, pp. $1576-1580,2008$.

[5] "Statistics Canada 2008," 2006 Community Profiles, July 2010, http://www12.statcan.ca/census-recensement/ index-eng.cfm.

[6] "Environment Canada," Weather Office, September 2011, http://www.climate.weatheroffice.gc.ca/climate_normals/index_e.html.

[7] L. Miller, X. Xu, and I. Luginaah, "Spatial variability of volatile organic compound concentrations in Sarnia, Ontario, Canada," Journal of Toxicology and Environmental Health A, vol. 72, no. 9, pp. 610-624, 2009.

[8] "Environment Canada. National Air Pollution Surveillance (NAPS) Network," June 2011, http://www.ec.gc.ca/ rnspa-naps/default.asp?lang=En\&n=5C0D33CF-1.

[9] A. Srivastava, B. Sengupta, and S. A. Dutta, "Source apportionment of ambient VOCs in Delhi City," Science of the Total Environment, vol. 343, no. 1-3, pp. 207-220, 2005.

[10] L. A. Smith, T. H. Stock, K. C. Chung et al., "Spatial analysis of volatile organic compounds from a communitybased air toxics monitoring network in Deer Park, Texas, USA," Environmental Monitoring and Assessment, vol. 128, no. 1-3, pp. 369-379, 2007.

[11] L. Miller, L. D. Lemke, X. Xu et al., "Intra-urban correlation and spatial variability of air toxics across an international airshed in Detroit, Michigan (USA) and Windsor, Ontario (Canada)," Atmospheric Environment, vol. 44, no. 9, pp. 1162-1174, 2010.

[12] R. R. Hoque, P. S. Khillare, T. Agarwal, V. Shridhar, and S. Balachandran, "Spatial and temporal variation of BTEX in the urban atmosphere of Delhi, India," Science of the Total Environment, vol. 392, no. 1, pp. 30-40, 2008.

[13] B. Barletta, S. Meinardi, F. S. Rowland et al., "Volatile organic compounds in 43 Chinese cities," Atmospheric Environment, vol. 39, no. 32, pp. 5979-5990, 2005.

[14] A. J. Buczynska, A. Krata, M. Stranger et al., "Atmospheric BTEX-concentrations in an area with intensive street traffic," Atmospheric Environment, vol. 43, no. 2, pp. 311-318, 2009.

[15] P. C. Chiang, Y. C. Chiang, E. E. Chang, and S. C. Chang, "Characterizations of hazardous air pollutants emitted from motor vehicles," Toxicological and Environmental Chemistry, vol. 56, no. 1-4, pp. 85-104, 1996.

[16] J. Liu, Y. Mu, Y. Zhang et al., "Atmospheric levels of BTEX compounds during the 2008 Olympic Games in the urban area of Beijing," Science of the Total Environment, vol. 408, no. 1, pp. 109-116, 2009.

[17] A. Gelencsér, K. Siszler, and J. Hlavay, "Toluene-benzene concentration ratio as a tool for characterizing the distance from vehicular emission sources," Environmental Science and Technology, vol. 31, no. 10, pp. 28692872, 1997.

[18] P. F. Nelson and S. M. Quigley, "The m,p-xylenes:ethylbenzene ratio. A technique for estimating hydrocarbon age in ambient atmospheres," Atmospheric Environment, vol. 17, no. 3, pp. 659-662, 1983.

[19] J. Zhang, T. Wang, W. L. Chameides, C. Cardelino, D. R. Blake, and D. G. Streets, "Source characteristics of volatile organic compounds during high ozone episodes in Hong Kong, Southern China," Atmospheric Chemistry and Physics, vol. 8, no. 16, pp. 4983-4996, 2008.

[20] A. J. Wheeler, M. Smith-Doiron, X. Xu, N. L. Gilbert, and J. R. Brook, "Intra-urban variability of air pollution in Windsor, Ontario-Measurement and modeling for human exposure assessment," Environmental Research, vol. 106, no. 1, pp. 7-16, 2008.

[21] D. O. Atari and I. N. Luginaah, "Assessing the distribution of volatile organic compounds using land use regression in Sarnia, Chemical Valley, Ontario, Canada," Environmental Health, vol. 8, no. 1, article no. 16, 2009.

[22] "Environment Canada. National Pollutant Release Inventory (NPRI)," June 2011, http://www.ec.gc.ca/pdb/ websol/querysite/query_e.cfm.

[23] M. M. Johnson, R. Williams, Z. Fan et al., "Participant-based monitoring of indoor and outdoor nitrogen dioxide, volatile organic compounds, and polycyclic aromatic hydrocarbons among MICA-Air households," Atmospheric Environment, vol. 44, no. 38, pp. 4927-4936, 2010. 
[24] K. F. Ho, S. C. Lee, H. Guo, and W. Y. Tsai, "Seasonal and diurnal variations of volatile organic compounds (VOCs) in the atmosphere of Hong Kong," Science of the Total Environment, vol. 322, no. 1-3, pp. 155-166, 2004.

[25] P. Bruno, M. Caselli, G. de Gennaro, L. Scolletta, L. Trizio, and M. Tutino, "Assessment of the impact produced by the traffic source on VOC level in the urban area of Canosa di Puglia (Italy)," Water, Air, and Soil Pollution, vol. 193, no. 1-4, pp. 37-50, 2008.

[26] X. M. Wang, G. Y. Sheng, J. M. Fu et al., "Urban roadside aromatic hydrocarbons in three cities of the Pearl River Delta, People's Republic of China," Atmospheric Environment, vol. 36, no. 33, pp. 5141-5148, 2002.

\section{This article should be cited as follows:}

Lindsay Miller, Xiaohong Xu, Amanda Wheeler, Dominic Odwa Atari, Alice Grgicak-Mannion, and Isaac Luginaah, "Spatial Variability and Application of Ratios between BTEX in Two Canadian Cities," TheScientificWorldJOURNAL, vol. 11, pp. 2536-2549, 2011. 

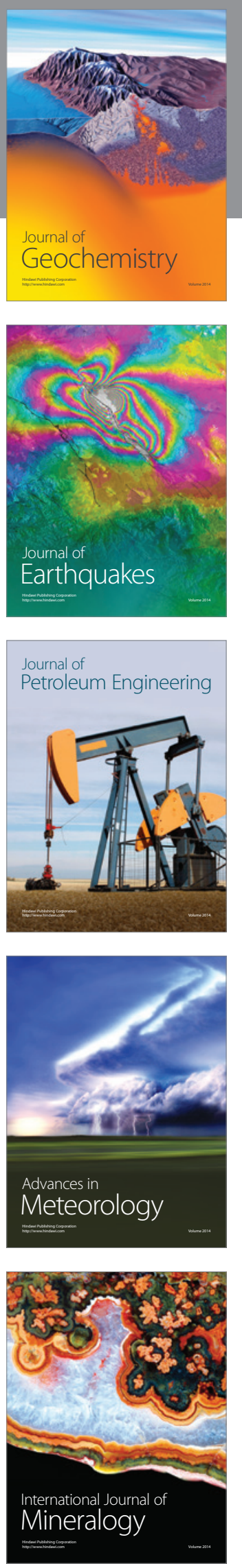
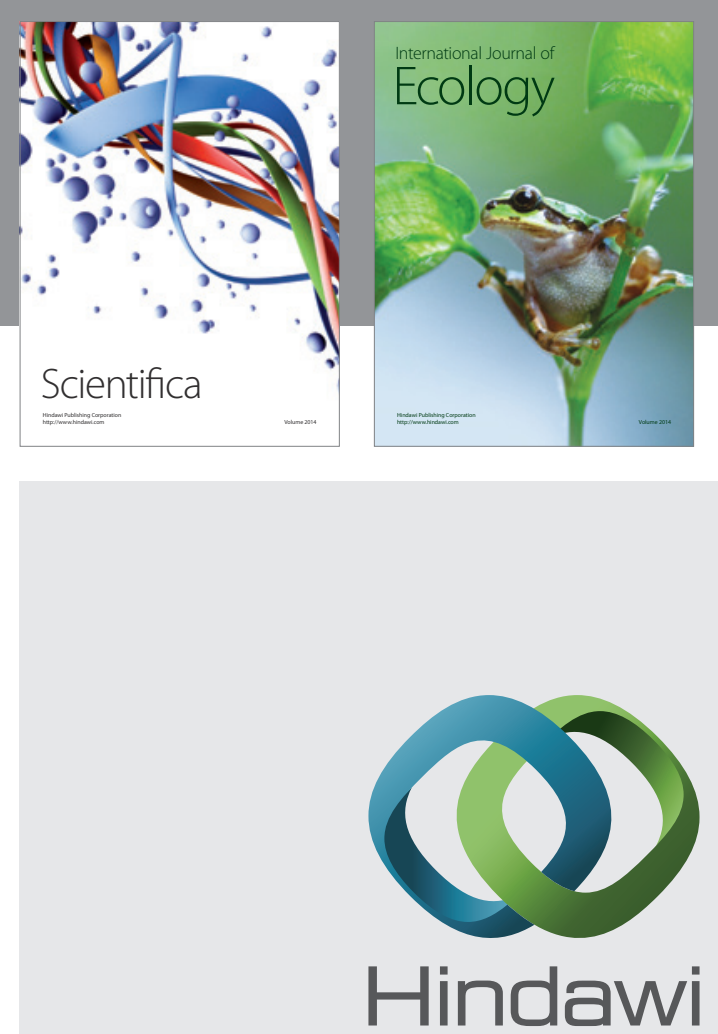

Submit your manuscripts at http://www.hindawi.com
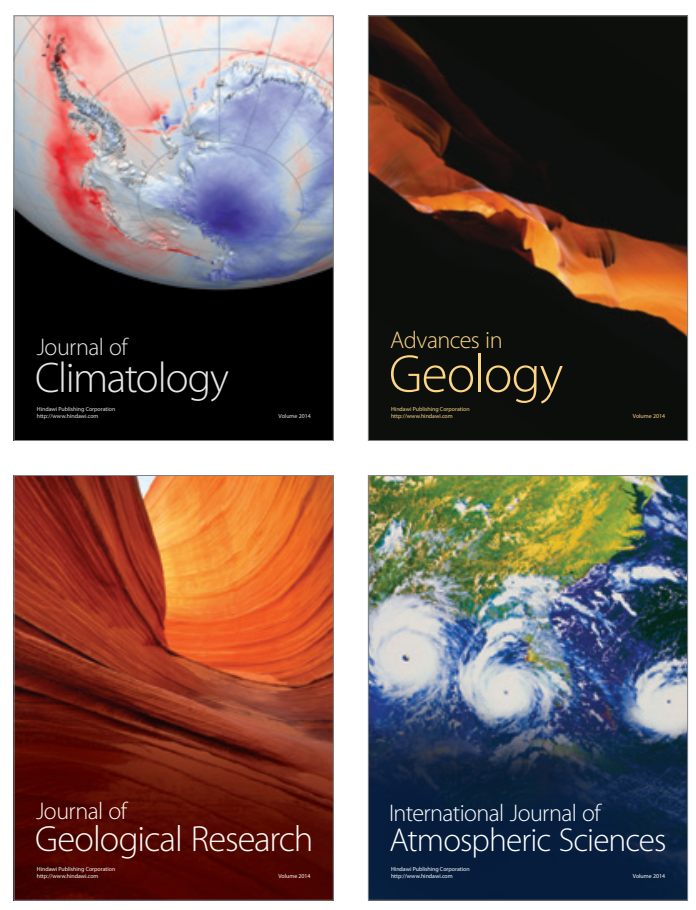
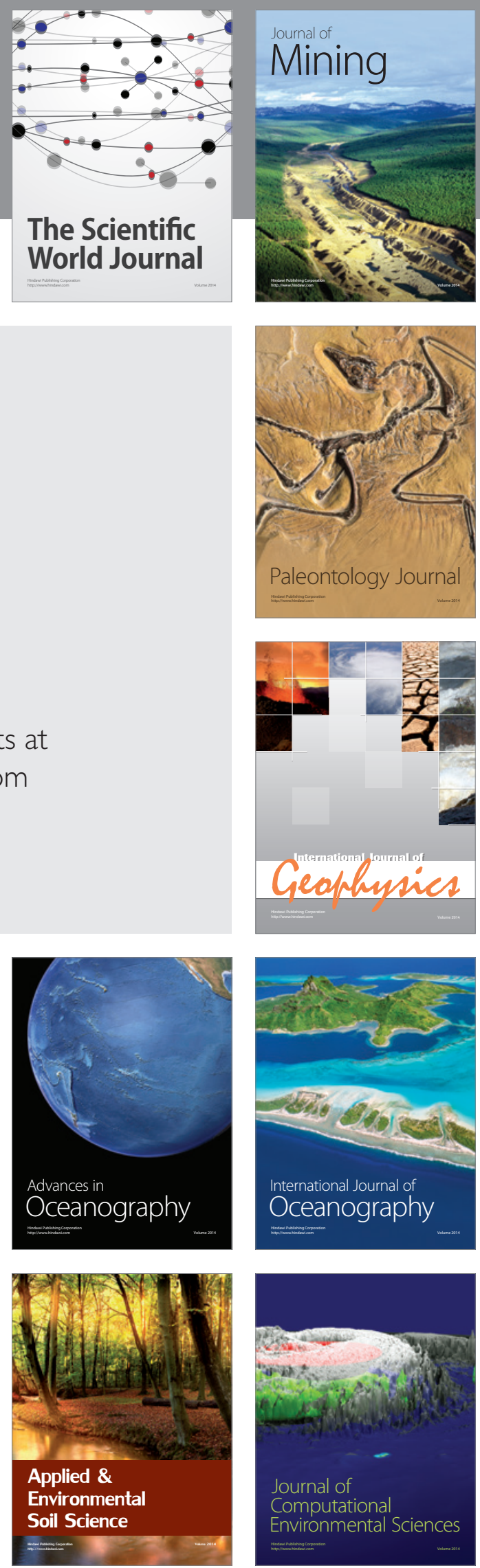